\title{
İstanbul'un Yeşil Alan Sorunları Çerçevesinde Yeşil Duvarların İrdelenmesi ve Öneriler
}

\author{
Ünal Akkemik ${ }^{1}$, Doğanay Tolunay ${ }^{2}$, Cihan Erdönmez ${ }^{3}$, Erdoğan Atmış $^{4 *}$, Oğuz Kurdoğlu ${ }^{5}$ \\ ${ }^{1}$ İstanbul Üniversitesi-Cerrahpaşa Orman Fakültesi Orman Botaniği Anabilim Dalı, 34473 Bahçeköy-Sarıyer, \\ İstanbul. \\ 2 İstanbul Üniversitesi-Cerrahpaşa Orman Fakültesi Toprak İlmi ve Ekoloji Anabilim Dalı, 34473 Bahçeköy- \\ Sarıer, İstanbul. \\ ${ }^{3}$ İstanbul Üniversitesi-Cerrahpaşa Orman Fakültesi Ormancılık Politikası ve Yönetimi Anabilim Dalı, 34473 \\ Bahçeköy-Sarıyer, İstanbul. \\ 4* Bartın Üniversitesi Orman Fakültesi Ormancılık Politikası Anabilim Dalı, Ağdacı Kampüsü, 74100, Bartın. \\ ${ }^{5}$ Karadeniz Teknik Üniversitesi Orman Fakültesi Orman Ekonomisi Anabilim Dalı, 61080, Trabzon.
}

\section{Öz}

Türkiye'nin en kalabalık büyükkenti olan İstanbul'daki kişi başına düşen yeşil alan miktarı dünya standartlarının oldukça altındadır. Artan nüfusun yeşil alan ihtiyacını karşılamaya dönük çalışmalar kapsamında farklı yeşil alan oluşturma ve bitkilendirme çalışmaları yapılmaktadır. Bunlardan biri olan yeşil duvarlar, bazı otoyol ve üstgeçitlerin kenarlarında oluşturulan, daha çok görselliğe dayanan yeşil altyapı uygulamalarındandır. Bu çalışma; sözü edilen yeşil duvar sistemlerinin kent ekosistemine katkılarını, yeşil alan/yeşil altyapı planlaması bağlamında irdelemek ve bu kapsamda öneriler sunmak amacıyla yapılmıştır. Yapılan değerlendirmeler ve tartışmalar sonucunda; İstanbul'daki yeşil duvarların mevcut haliyle ekosisteme katkısının çok düşük hatta çok önemsiz düzeyde olduğu, yeşil altyapının gerektirdiği kamusal planlama anlayışına uygun olmadığı ve hem ekonomik hem de ekolojik maliyetlerinin çok yüksek olduğu anlaşılmıştır. Otoban kenarlarında yeşil duvarlar oluşturma uygulamaları yerine, kent ekosistemine katkısı çok daha yüksek ve maliyeti çok daha düşük olan alan kullanımları ve bitkilendirme çalışmalarının hayata geçirilmesi hem ekolojik hem de toplumsal açıdan daha yararlı olacaktır.

Anahtar Kelimeler: Dikey bahçe, İstanbul, kent ekosistemi, yeşil alan, yeşil altyapı.

\section{Evaluation of Green Walls and Suggestions in Terms of Green Space Problems of Istanbul}

\begin{abstract}
In Istanbul, which is the most crowded metropolitan of Turkey, the amount of green space per person is below the world standards. Within the scope of the studies aimed at meeting the green space needs of the increasing population, different green areas creation and vegetation studies are carried out. One of these green areas is green wall, which is one of the green infrastructure applications that are formed on the edges of some highways and overpasses, and are mostly based on visuality. The aim of the paper is to examine the contributions of the aforementioned green wall systems to the urban ecosystem in the context of green space / green infrastructure planning and to offer suggestions in this context. As a result of the evaluations and discussions, it has been understood that the contribution of the green walls in Istanbul to the ecosystem is very low or even insignificant the green infrastructure is not suitable for public planning understanding and that both economic and ecological costs are high. Instead of creating green walls on the sides of the highway it will be more beneficial both ecologically and socially to implement land use and planting studies, which have a much higher contribution to the urban ecosystem and much lower cost.
\end{abstract}

Keywords: Vertical garden, Istanbul, urban ecosystem, green space, green infrastructure.

\section{*Sorumlu Yazar (Corresponding Author):}

Erdoğan Atmiş (Prof. Dr.); Bartın Üniversitesi, Orman Fakültesi, Orman Mühendisliği

Bölümü, 74100, Bartın-Türkiye. Tel: +90 (378) 223 5139, Fax: +90(378)2235062,

E-mail: eatmis@bartin.edu.tr ORCID:0000-0002-0300-4096
Geliş (Received) : 11.01 .2021

Kabul (Accepted) : 12.04.2021

Basım (Published) : 15.04.2021 


\section{Giriş}

İstanbul; 8 bin 500 yıllık bir tarihe sahip olan ve yaklaşı 530 bin ha alanda 16 milyondan fazla insanı barındıran; son 50 yılda nüfusunun hızla artışına bağlı olarak çok çarpıcı bir arazi dönüşümü yaşayan bir büyükkenttir. Şahin (2020)'e göre İstanbul'da 1971 yılından 2018 yılına kadar ormanlar \%10, tarım alanları ise \%33,5 azalırken, yerleşim alanları \%409,7 artmıştır. Benzer biçimde Cengiz vd. (2019)'e göre 1984 ile 2017 yılları arasında ormanlar \%11,6, tarım alanları \%27,3 azalırken, yerleşim alanları \%183,5 artmıştır.

İstanbul'da tarım ve orman alanındaki azalma ve yerleşim alanlarındaki aşırı büyüme, beraberinde doğal ve kentsel alanlarda önemli çevre sorunlarını ortaya çıkarmıştır. Orman ve tarım alanlarının azalmasıyla birlikte tutulan karbon miktarında azalma meydana gelmiş, yaban hayatı ve su rezervleri zarar görmüş, bunun sonucu olarak bitkiler tarafından üretilen oksijen miktarı da önemli oranda azalmıştır. Örneğin, yalnızca 2009-2016 yılları arasındaki 7 yıllık dönemde, İstanbul'un kuzeyindeki orman alanlarında gerçekleştirilen yol, köprü ve havalimanı projeleri nedeniyle 15 bin hektar orman alanının yok olduğu ve diğer arazi kullanım değişiklikleriyle birlikte 4,4 milyon ton $\mathrm{CO}_{2}$ 'nin atmosfere salındığı saptanmıştır (Doğru vd., 2020).

Kentsel ortamlarda açık yeşil alan değerlendirmesiyle ilgili en yaygın ölçü, kişi başına düşen yeşil alan miktarıdır. Yeşil alan kavramı, 2017 yılında yayımlanan Planlı Alanlar İmar Yönetmeliğinde "Toplumun yararlanması için ayrılan oyun bahçesi, çocuk bahçesi, dinlenme, gezinti, piknik, eğlence ve rekreasyon alanlarının toplamı (Metropol ölçekteki fuar, botanik ve hayvanat bahçeleri ile bölgesel parklar bu alanlar kapsamindadır.)" şeklinde tanımlanmaktadır. Bu tanımdan da anlaşılacağı üzere yeşil alan kavramı alanın bitki dokusuna dair bir bilgi vermemektedir. Üzerinde hiç ağaç olmayan ve çok az bitki içeren alanlar da yeşil alan olarak tanımlanabilmekte ve "sosyal açık ve yeşil alanlar" olarak ifade edilebilmektedir (Çabuk, 2019). Ancak kamuoyunda yeşil alan denince; bir kentte insanların kolaylıkla ulaşabildiği, rekreasyon ihtiyacını karşılayabildiği, kent için oksijen üretme potansiyeline sahip, kentsel 1sı adası etkisini azaltabilecek büyüklüklerde ve genellikle ağaç örtüsüyle kaplı olan sahalar anlaşılmaktadır. Ayrıca yeşil alanların bir kısmı insanların kullanımına kapalı olabilmektedir. Böylece yeşil alanlar kullanım durumuna göre;

- Aktif yeşil alanlar: Korular, parklar, ortak yeşil alanlar, mesire alanları gibi doğrudan insanların yararlanabildiği alanlar,

- Pasif yeşil alanlar: Yol kenarları, mezarlıklar, özel bahçeler, kamu kurumlarına ait bahçeler gibi doğrudan yararlanmaya açık olmayan alanlar olarak sınıflandırılmaktadır (Gül vd., 2020).

Kentlerdeki yeşil alanlar, serinletici etkileri, karbon bağlamaları, yağış sularının yüzeysel akışa geçmesini engelleyerek selleri önlemeleri gibi faydaları nedeniyle iklim değişikliğinin olumsuz etkilerinin azaltılmasına katkı sağladıkları için giderek daha da önem kazanmaktadır. İstanbul özelinde yeşil alanlar aynı zamanda deprem toplanma alanı olarak da işlev görmektedir. Ancak İstanbul; kent içindeki birçok yeşil alanın imara açılıyor olması gibi nedenlerle yeşil alanlarını kaybetmekte ve kente yeni yeşil alanlar kazandırılıyor olsa bile, nüfus artışına bağlı olarak kişi başına düşen yeşil alan miktarı azalmaktadır.

Park ve bahçelerin kent içinde kapladığı alanlar diğer bazı büyük kentlerle karşılaştırıldığında İstanbul'un durumu aşağıdaki gibidir (World Cities Culture Forum, 2021):

- $\quad$ Singapur \%47

- Viyana $\% 45,5$

- Stockholm \%40

- Zürih \%41

- Roma \%38,9

- Londra \%33

- $\quad$ New York \%27

- Lizbon $\% 22$

- $\quad$ Paris \%9,5

- İstanbul \%2,2

İBB verilerine göre 2019 yılı sonu itibarıyla İstanbul'da $106.097 .276 \mathrm{~m}^{2}$ aktif yeşil alan ve $93.525 .049 \mathrm{~m}^{2}$ pasif yeşil alan bulunmaktadır (ïBB, 2020). Buna göre kişi başına düşen aktif yeşil alan $7,04 \mathrm{~m}^{2}$ ve pasif yeşil alan 6,21 $\mathrm{m}^{2}$ kadardır. Parklar, korular, hobi bahçeleri, mesire alanları ve tabiat parkları aktif yeşil alanlar içinde gösterilirken, kent içindeki insanların kullanmadığı ağaçlık alanlar, mezarlıklar, fidanlıklar ve refüjler de pasif yeşil alanlar içinde verilmiş̧ir. Bu verilerden İstanbul'da aktif ve pasif yeşil alan ayırmaksızın bakıldığında yaklaşık olarak 200 milyon $\mathrm{m}^{2}$ kadar yeşil alan olduğu ve kişi başına düşen yeşil alan miktarının $13,25 \mathrm{~m}^{2}$ olduğu 
sonucunu çıkarmak mümkündür, ancak bu şekildeki bir değerlendirme, gerçek durumun gözden kaçmasına neden olacaktır. Çünkü pasif yeşil alanlar kentlilerin kullanımına kapalı olduğu için herhangi bir rekreatif amaçla kullanılamamaktadır. 7,04 $\mathrm{m}^{2}$ olarak verilen kişi başına düşen aktif yeşil alan miktarı ise kent içi ve kent dişında yer alan kentlilerin kullandığı alanların miktarıdır. Ancak kent çeperinin dışında kalan ve erişilebilirlikleri sınırlı olan mesire alanları ve tabiat parkları toplam aktif yeşil alanın \%74'ünü oluşturmaktadır. Çoğu depremde toplanma alanı olarak kullanılan, kenti serinleterek ve yağış sularının toprağa sızmasını sağlayarak iklim değişikliğinin kent üzerindeki olumsuz etkilerini azaltan ve erişilebilirliği daha yüksek olan kent içindeki parklar, korular ve hobi bahçelerinin toplam alanı ise sadece $27.825 .804 \mathrm{~m}^{2}$ 'dir ve bunların kişi başı miktarı 1,85 $\mathrm{m}^{2}$ kadardır.

İBB son 10-15 yıldır pasif yeşil alan olarak değerlendirilen orta refüj, yol kenarı bitkilendirmeleri ile yol kenarlarındaki dikey bahçe uygulamalarına ağırlık vermiştir. Bu türdeki pasif yeşil alanlarda ithal bitki türlerinin kullanılması, çim alanların yoğun olması nedeniyle su tüketiminin de artması, gübreleme ve diğer bakım maliyetlerinin de fazlalığı nedeniyle yol kenarı bitkilendirmeleri ve dikey bahçe uygulamaları her zaman tartışmaya konu olmuştur. Bu tartışmalar üzerine İstanbul Büyükşehir Belediye Başkanlığı (İBB) Park Bahçe ve Yeşil Alanlar Daire Başkanlığı 2020 sonbahar aylarında birkaç noktada dikey bahçe uygulamalarından vazgeçerek özellikle bazı yol kenarlarını boyama yönünde adımlar atmıştır. Ancak İBB'nin bu kararı İstanbul'un yeşil alan miktarının azaldığı, dikey bahçelerin kentin serinlemesine katkı sağladığı, karbon depoladığı, hava kalitesi ve sıcaklığını dengelediği gibi gerekçelerle eleştirilmiştir (Öztürk, 2020). Bu eleştirilerde aktif ve pasif yeşil alan kavramlarının karıştırıldığı, birbirinden farklı kavramlar olan ve farklı ekolojik işlevlere sahip yağmur bahçesi, yeşil koridor, dikey bahçe, yeşil çatı uygulamalarının genelleştirilerek verildiği görülmüştür.

"Yeşil duvarlar" ya da "dikey bahçeler" terimi modern anlamda ilk defa Fransız botanikçi Patrick Blanc tarafından ortaya konmuştur. Blanc kentlerde, duvar üzerinde bitkileri yetiştirmeyi planlamış ve "yaşayan duvarlar' adını verdiği uygulamayı ilk kez 1994’te Chaumont Bahçe Festivalinde sergilemiştir. Bu uygulama daha sonra birçok yerde hayata geçirilmiştir (Ekşi, 2020). Ancak bu konuda da farklı isimlendirmelerden kaynaklanan bir kavram kargaşası bulunmaktadır. Bu çalışmada; Manso ve Castro-Gomes (2015) tarafından söz konusu karmaşıklığı gidermek amacıyla önerilen "yeşil duvar sistemleri” kavramından esinlenerek "yeşil duvarlar" kavramı tercih edilmiştir. Bu bağlamda makalenin amacı, özellikle otoyol kenarlarındaki yeşil duvarların İstanbul ekosistemi ve yeşil alan/yeşil altyapı planlaması açısından değerlendirmesini yapmak ve kent ekosistemine katkısını irdelemektir.

\section{Yeşil Duvarlar ve Kent Ekosistemine Katkı Potansiyelleri}

Yeşil duvar sistemleri oldukça çeşitlidir. Bazılarında bitkiler saksılarla duvarlara monte edilmekte, saksılardaki bitkiler tek yıllık ya da çok yıllık olabilmektedir. Bazıları ise toprakta yetiştirilen çok yıllık sarılıcı bitkilerin duvarları kaplamasıyla oluşturulmaktadır. Saksılarla oluşturulan yeşil duvarlardaki bitkilerin hem yatırım hem de bakım maliyetleri oldukça yüksektir. Buna karşılık sarılıcı bitkilerle oluşturulan yeşil duvarların, zaman zaman budanması haricinde herhangi bir bakım maliyeti bulunmamaktadır. Bu nedenle ikinci yöntemin sürdürülebilirlik açısından daha avantajlı olduğu söylenebilir.

İrdeleme konusu olan yeşil duvarların kaldırılmasına karşı çıkanlar tarafından "yeşil duvarların oldukça yararlı olduğu, karbon depoladı̆̆g, gürültüyü önlediği, kentin serinlemesine katkısı olduğu, yeşil duvarların kaldırılmasının kişi başına düşen yeşil alanların miktarını azalttığı" yönünde açıklamalar yapılmıştır (Öztürk, 2020). Bu tartışmaların ışığı altında yeşil duvarların (Şekil 1-3) kent ekosistemine katkıları aşağıda verildiği şekilde değerlendirilmiştir:

Yeşil alan miktarının artırılmasına etkisi: İstanbul'da İBB tarafından tesis edilen yeşil duvarlar, resmi verilere göre 45 bin $\mathrm{m}^{2}$ 'dir ve yeşil alan envanterinde pasif alan içinde gösterilmektedir. İstanbul'un aktif ve pasif toplam yeşil alan miktarı 199.632.325 $\mathrm{m}^{2}$ olduğuna göre; yeşil duvar uygulamasının toplam yeşil alan miktarına katkısı $\% 0,02$ (on binde iki) civarındadır.

Kaldırılan yeşil duvarlar saksılı bitkilerle oluşturulmuş sistemlerdir ve İBB Park Bahçe ve Yeşil Alanlar Daire Başkanlığı verilerine göre tesis maliyeti normal yeşil alan tesis maliyetinin 9 katı kadar olan bir uygulamadır. Diğer yandan yeşil duvarların ilgili yönetmeliklerde de belirtildiği üzere aktif yeşil alan değildir ve İBB verilerinde de aktif yeşil alanlar arasında gösterilmemektedir. Ayrıca ekolojik olarak da sağladıkları hizmetler ve işlevler kent parkları ve ormanları gibi alanlara oranla oldukça düşüktür. Bu bağlamda Ekşi (2020) de; “dikey bir yüzeyde oluşturulan otsu bitkilerle kaplı alanların görsel bir etkisi dışında çok belirgin bir ekolojik katkısı olmadı̆̆ını, son yıllarda ciddi biçimde yapılaşan bu kentte, bu tip tartışmaların yerine, iklim değişikliği ve karbon 
ayak izi gibi etkilerin azaltılmasında belirgin etkisi olduğu bilinen ve bakım ihtiyaçları düşük olan uygun ağaç türlerinin düşünülmesinin doğru olacağını" belirtmiştir. Bu kapsamda kentin yeşil alanlarının arttırılmasında düşük maliyetli uygulama ve sistemlerin tercih edilmesi daha yararlı olacaktır.

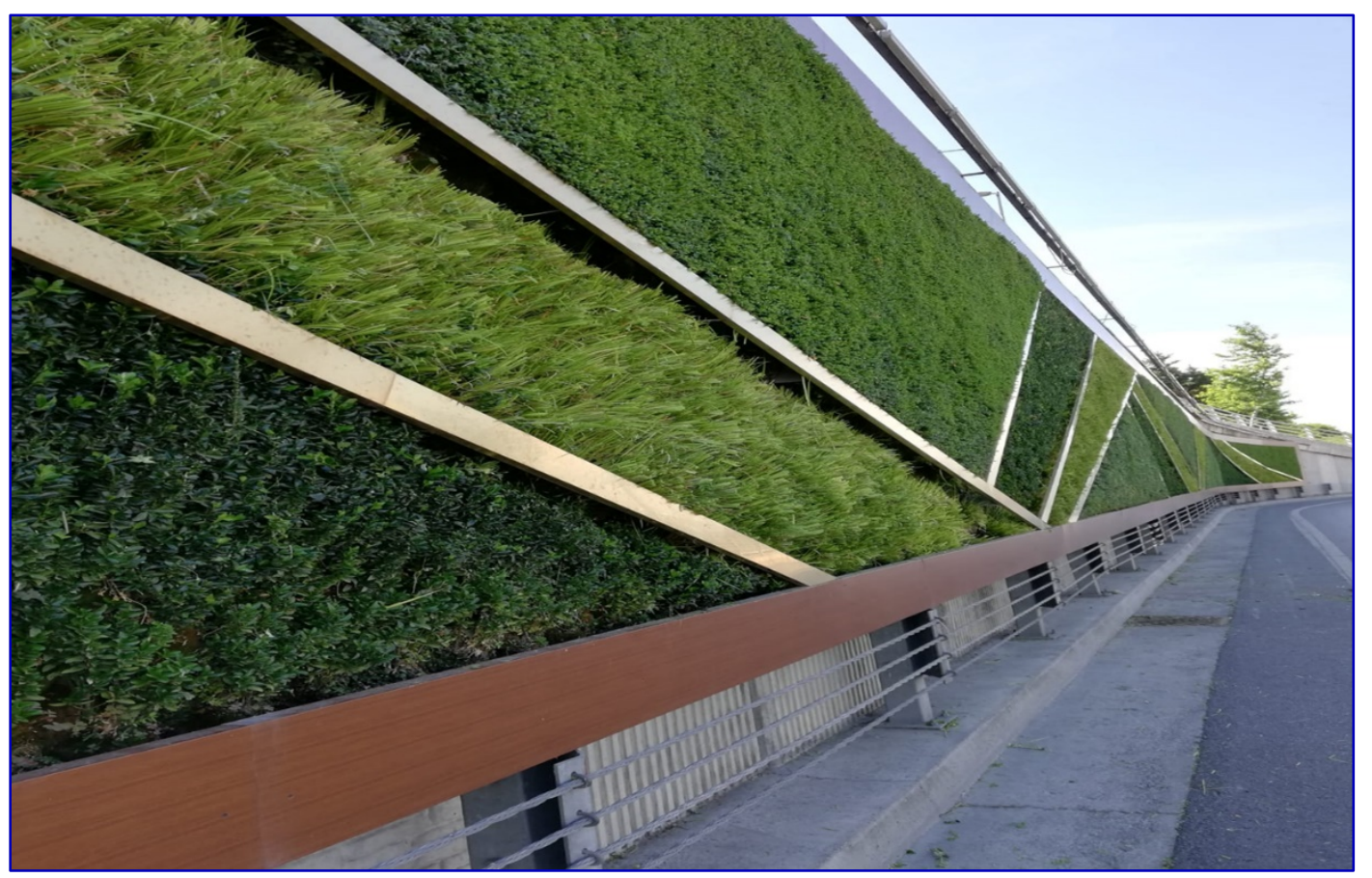

Şekil 1. Atatürk Havalimanı dış kısmındaki yol kenarında bir yeşil duvar uygulaması (Foto: IBB Arşivi)

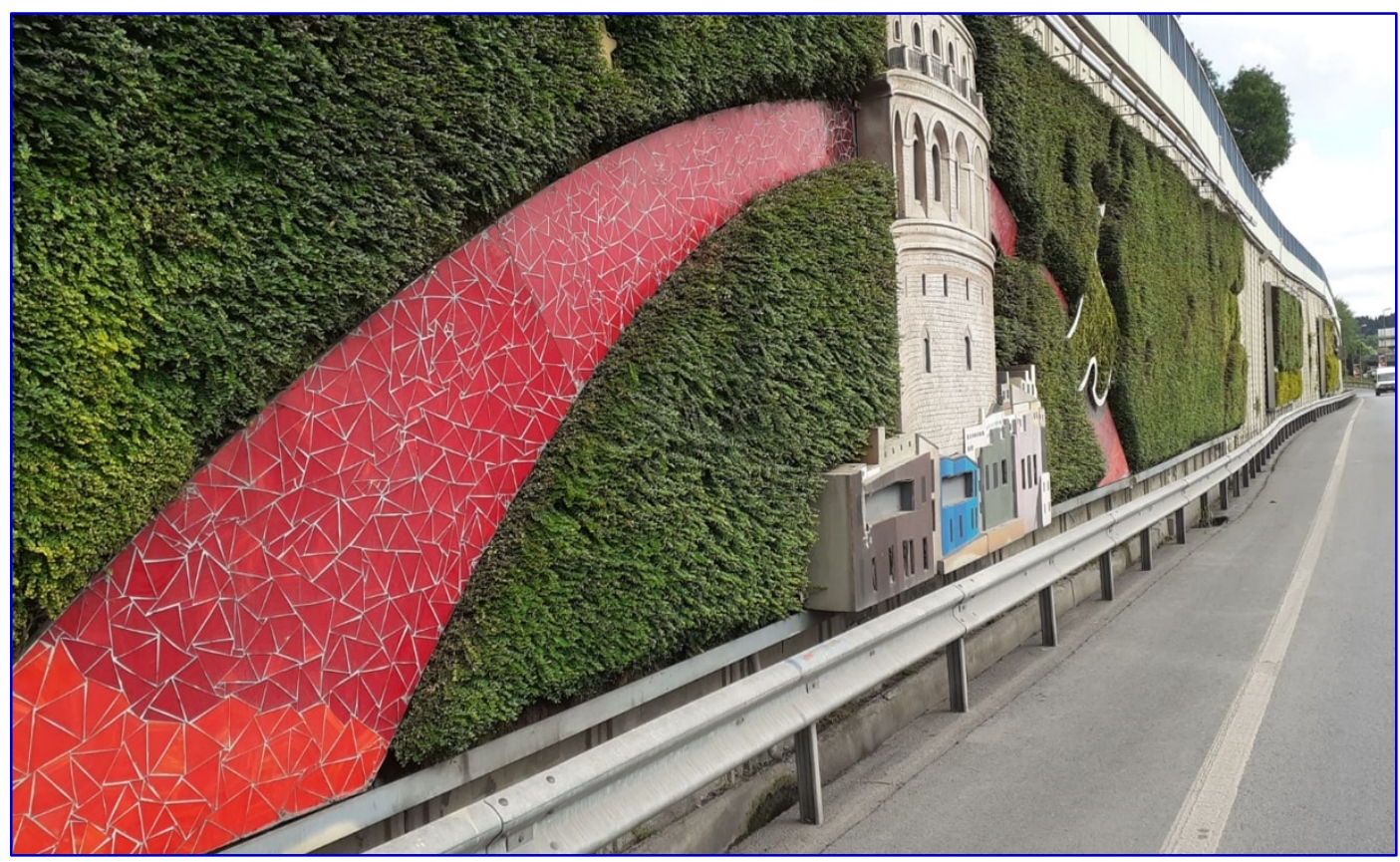

Şekil 2. Topkapı-Maltepe yol kenarında bir yeşil duvar uygulaması (Foto: IBB Arşivi). 


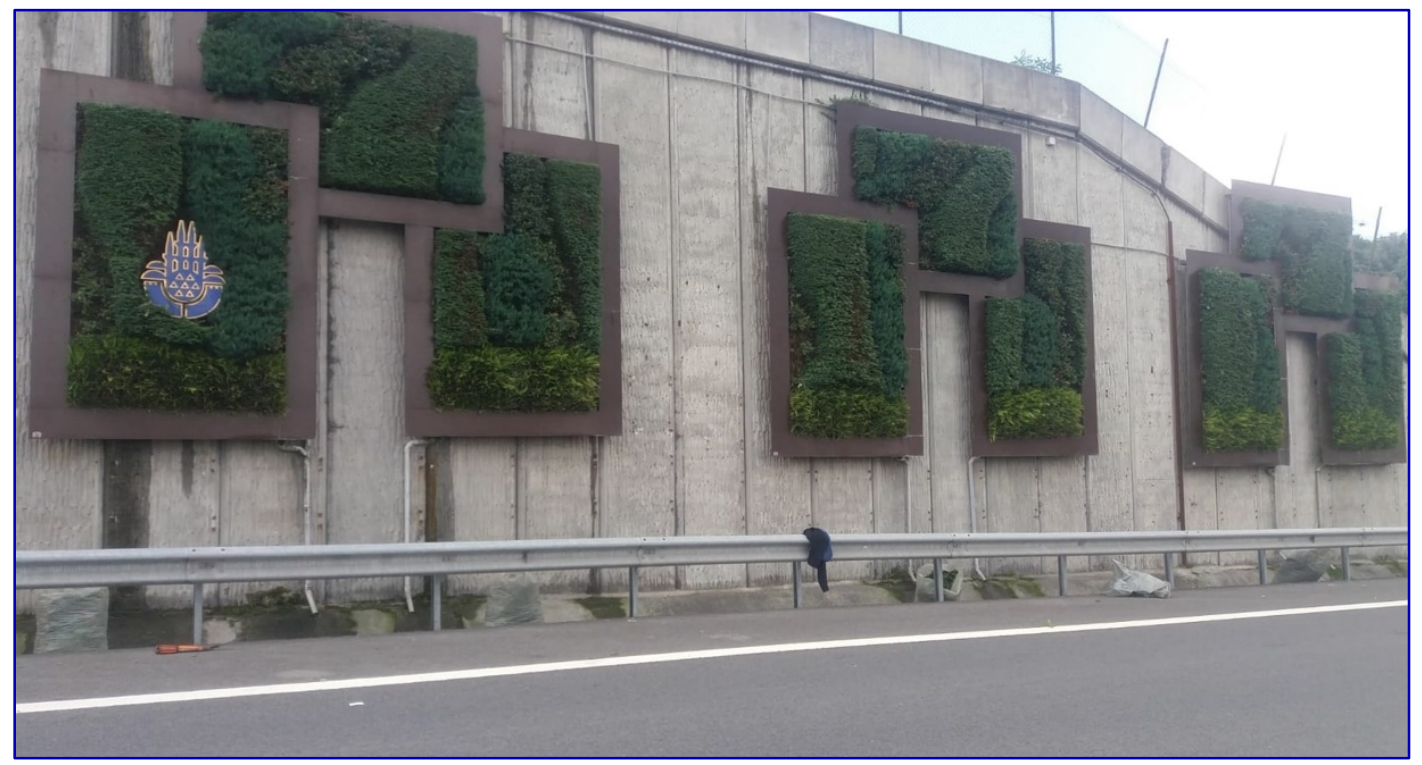

Şekil 3. Seyrantepe yol kenarında bir yeşil duvar uygulaması (Foto: IBB Arşivi).

Şehrin serinletilmesine etkisi: Otoyol kenarlarındaki yeşil duvarlar yayaların kullandığı alanlar olmadıkları için sadece üzerinde bulundukları duvarı serinletme potansiyeline sahiptir. Bilimsel olarak, kent içindeki serinleme etkisine sahip bitkiler ağaçlardır. Bu yönde çok sayıda çalışma bulunmaktadır. Ormanlar ve farklı bitkilerden oluşan parklar ile park ve orman dışında alanlarda ölçülen sıcaklık değerlerindeki farklılıklar, orman ve parkların önemi ortaya koymaktadır.

o Nichol (1996) yaptığı bir çalışmada, ağaçlık alanlar, çimen ve beton yüzeyler için sıcaklık değerlerini belirlemiştir. Buna göre en düşük sıcaklık $28,7^{\circ} \mathrm{C}$ ile ağaç gölgesinde tespit edilmiştir. Ortalama yüzey sıcaklıkları sırasıyla ağaçlık alanda $32,9{ }^{\circ} \mathrm{C}$, çimenlik alanda $35,6{ }^{\circ} \mathrm{C}$ ve beton yüzeyli alanda $40,7^{\circ} \mathrm{C}$ olarak ölçülmüsşür.

o Yu ve Hien (2006) Singapur'da gece ve gündüz sıcaklık farklarını ağaçlı, ağaçsız açık alan ve binaların olduğu alanlar açısından karşılaştırmış ve ağaçlı alanların binaların olduğu alanlara göre daha serin olduğunu belirtmiştir.

o Jauregui (1990) Meksiko City’de, yaklaşı 500 hektar büyüklüğündeki Chapultepec Parkı'nın ortam sıcaklığını $2-3{ }^{\circ} \mathrm{C}$ azalttığını belirtmiştir. Fark sıcak aylarda $4{ }^{\circ} \mathrm{C}$, nemli aylarda ise $1{ }^{\circ} \mathrm{C}$ 'dir.

o Yan vd. (2018) Çin'de yaptıkları çalışmada parkın soğutma etkisinin 0,6-2,8 ${ }^{\circ} \mathrm{C}$ olduğunu ve bu etkinin parktan 1,4 km mesafeye kadar azalarak devam ettiğini belirtmişlerdir.

o Oliveira vd. (2011) bir sahil kenti olan Lizbon'da parkın soğutma etkisinin 5-7 C'ye kadar çıktığını belirlemiştir.

o Daha sıcak bölgelerde ağaçların havayı serinletme etkisi de daha yüksektir. Örneğin Cezayir Saharan’da bu etki $8{ }^{\circ}$ C'ye kadar çıkmaktadır (Boudjellal ve Bourbia, 2018).

$\mathrm{Bu}$ çalışmalar göstermektedir ki, gölge ve serinletme etkisi ağaçlara özgüdür. Ağaçların bile toplu halde sıcaklığ düşürme etkisi ortalama 2-3 ${ }^{\circ} \mathrm{C}$ 'dir ve bu değer en fazla 7-8 ${ }^{\circ} \mathrm{C}$ 'ye ulaşabilmektedir. Bu nedenle ne çim alanların ne de dikey yeşil duvarların serinletme etkisinin önemli düzeye ulaşabileceğinden bahsedilebilir. Bu yüzden kent içerisindeki yaşam alanlarından uzak beton zeminlerin serinletilmesi için duvarların çok yüksek maliyetli bitkilerle kapatılması yerine geniş alan kaplayan parkların uygun türlerle ağaçlandırılması hem çok daha ucuz hem de en akılcı yaklaşımdır. Kaldı ki iklim değişikliğiyle mücadelede öncelik kent içindeki ağaçlıklı yeşil alanların miktarının arttırılmasına verilmektedir.

Bununla birlikte, Perez vd. (2011) Akdeniz çevresindeki bazı binaların duvarlarını kaplayan sarmaşık şeklinde ve kökleri toprakta olan bitkilerin bina duvarlarında 1sı yalıtımına önemli katkılar yaptığını belirtmiştir. En sıcak dönem olan Ağustos-Eylül aylarında sarmaşık kaplı olan ve olmayan duvar arasındaki farkın ortalama 5,5 ${ }^{\circ} \mathrm{C}$ ve maksimum 15,5 ${ }^{\circ} \mathrm{C}^{\prime}$ ye kadar çıktığını belirtmişlerdir. Bu uygulamanın binaları serinletmek için yapıldığını ve İBB tarafından yapılan yeşil duvar uygulamasından tamamen farklı bir metot olduğunu unutmamak gerekir. Ayrıca Hacıosman Yokuşu'ndaki köprü çevresinde olduğu gibi bazı sarmaşıklı yeşil duvar uygulamalarının İstanbul'da halen varlığını sürdürmekte olduğunu hatırlatmak gerekir. 
Yüzey sularının yönetimine etkisi: Beton duvarlar üzerine dikilen ve otsu bitkilerden oluşan yeşil duvarların tükettiği su ve harcanan kimyasal madde miktarı düşünüldüğünde, oluşan zararın, faydasından oldukça fazla olduğu görülecektir. Yüzey sularının yönetimi ancak toprak yüzeylerdeki diri örtü ile mümkündür. İBB tarafından tesis edilen yeşil duvarlar, tüm yüzeyi kaplamadığından ve genellikle geometrik şekiller içerdiğinden yüzey sularını yönetecek bir potansiyeli de söz konusu değildir. Hızal ve Serengil (2008) Elmalı Havzası'ndaki nadas alanları ile çayır ve ormanlık alanlarda yıllık 1336,2 mm olan yağışın yüzeysel akışa geçiş şekillerini çalışmışlar ve nadasa bırakılan alanda suyun \%56'sının, çayırlık alanda \%36'sının ve ormanlık alanda da suyun \%18'inin yüzeysel akışla gittiğini belirtmişlerdir. Beton zeminlerde ise bu oran \%100'lere varmakta olduğuna göre İstanbul'un gerçek ihtiyacı, otoyol kenarındaki beton zeminlere inşa edilmiş yeşil duvarlar değil, yüzey sularının akışa geçmesini azaltacak şekilde oluşturulmuş, otsu bitki, çalı ve ağaçlarla kurulmuş park ve orman alanlarıdır.

Hava kalitesi iyileştirilmesi ve să̆glklı yaşamın sağlanmasına etkisi: Egzoz gazı salımının yoğun olduğu otoyol kenarlarında hem gürültüyü hem de kirli havayı absorbe edecek olan öncelikli bitkiler bir perde görevi de gören ağaçlardır. İstanbul'da yeşil duvarlardaki otsu türlerin hava kalitesini ağaçlar kadar iyileştirmesi mümkün değildir. Çünkü bitkilerin hava kalitesini arttırması ve toksik bazı gazlar ile tozları absorbe etmeleri yaprak yüzey alanı ile ilgilidir. Stomalardan alınan toksik gazların konsantrasyonları çok yüksek miktarlara ulaştığında bitkiler zarar görmektedir. Egzoz gazlarının çok yoğun olduğu yerlerdeki yeşil duvarlarda da bu durum yaşanmış ve kuruyan bitkilerin yerine sürekli tamamlamalar yapılmıştır. Bu da yeşil duvarların bakım maliyetini artırmıştır.

Yeşil duvarların sağlıklı yaşam imkanı sağladığı da söylenemez. Çünkü bu duvarların çoğu insanların kullandığı alanlarda yer almamaktadır. Diğer yandan bitkiler yoğun stres koşullarında atmosfere saldıkları biyojenik kökenli uçucu organik bileşikleri (BVOC) kendilerini korumak amacıyla artırmaktadır (Nowak, 2000; Nowak vd., 2013; Dominguez-Taylor vd., 2007’ne atfen Koca vd. 2013). Bu biyojenik emisyonları, havanın kirli olduğu ortamlarda bitkiler kendini korumak için salmakta ve kirli ortamdaki azot oksitlerin (NOx) varlığında ozon oluşturmaktadırlar. Bu durum, yoğun stres altındaki bitkilerin faydadan çok zarar getirdiğinin bir göstergesidir. O nedenle bir yandan su, bir yandan kısıtll toprak ve diğer yandan da yoğun egzoz gazl ve yüksek slcaklık etkisine maruz kalan yeşil duvarlardaki otsu bitkilerden hava kalitesini iyileştirmesini beklemek bilimsel bir yaklaşım değildir. Ağaçlar, toprak zeminde olduğundan ve kökleriyle çoğu zaman yeterli suyu alabildiğinden zehirli gazları daha fazla absorbe etme potansiyeline sahiptir. Ağaçlar biyojenik emisyon salgılamalarına ve ozon oluşumuna neden olmalarına karşın yüksek oranda karbondioksit de depoladıklarından bir denge sağlamaktadır.

Gürültünün azaltılmasına etkisi: Bu konuda yapılmış bir çalışmaya göre; 4 şeritli ve $\% 85$ hafif, \%15 ağır taşıt trafiğine sahip bir otoyolda yeşil duvarın, önündeki yayalar için gürültüyü 5-6 desibel kadar azalttığı belirtilmiştir (Renterghem vd., 2015). Fakat bu çalışma o yolu kullanan yayaların durumunu değerlendiren bir çalışmadır. İstanbul'da otoyol kenarındaki yeşil duvarlar genel olarak yayalara kapalıdır. Bu durumda yeşil duvarların yayalara fayda sağlaması söz konusu olmayacaktır.

Karbon tutma potansiyelinin artırılmasına etkisi: Zaid vd. (2018) çeşitli kaynaklara dayandırarak yeşil duvarlardaki bazı bitkilerin metrekarede yaklaşık 0,05- 0,94 kg CO 2 absorbe ettiğini belirtmiştir. Bununla birlikte, yer örtücüler tarafından tutulan karbonun ağaçlara kıyasla daha az olduğunu ifade etmişlerdir. Yazarlar bu çalışmada; tropik ülkelerdeki kentlerde yeşil duvarların estetik, sosyal ve çevresel faydaları olduğuna değinmiş, fakat buna karşın uzun vadeli çevresel etkilerle dengeyi sağlama ve kentsel alanlar için iklim değişikliğini azaltma stratejisinin güçlü bir paydası olma iddiasının tartışmalı olduğunu belirtmişlerdir. Nitekim yeşil duvarlardaki bitkiler çok yıllık olsalar da ağaçlara göre ömürleri oldukça kısadır ve öldükten sonra bağlamış oldukları karbon, ayrışma sonucunda yeniden atmosfere dönmektedir.

Biyolojik çeşitliliğe etkisi: Yeşil duvarların biyolojik çeşitliliğe etkisi kullanıldıkları yerlere ve bitki türü seçimine göre değişecektir. Kirlilikten ve gürültüden uzak yerlerde, çiçekli bitkilerin kullanıldığı yeşil duvarların çeşitli böcek ve kelebek türlerine habitat oluşturması mümkündür. Ancak tartışılan yeşil duvarlarda kullanılan türlerin genellikle çiçeksiz olması ve gürültü ile kirlilikten dolayı buralarda böcek ve kelebeklerin yaşaması oldukça zordur.

Ayrıca yeşil duvarlardaki bitkilendirme ile ilgili iki önemli noktanın altını çizmekte yarar vardır;

1. Yeşil duvarlardaki bitkiler, otsu bitkiler olduğu için bunların ömürleri en çok birkaç yıldır. O nedenle, ağaçlar gibi karbon tutma potansiyelleri yoktur ve sera gazı emme konusunda bir çözüm değillerdir.

2. İBB Park Bahçe ve Yeşil Alanlar Daire Başkanlığı verilerine göre maliyeti normal yeşil alan tesislerine göre yaklaşık 9 kat daha yüksek olan tesislerdir. Bir kez yapıldığında hemen her gün bakım ve sulama gerektiren bir uygulamadır. Manso ve Castro-Gomes (2015) de süreklilik açısından yeşil duvarların 
halen yüksek su ve besin tüketimi ile sık bir bakım gerektirdiğini belirtmiştir. O nedenle bu uygulama, ekolojik bir yaklaşım değildir.

\section{Yeşil Alan/Yeşil Altyapı Anlayışı l̇çinde Yeşil Duvarların Yeri}

Dünyada kentsel yeşil alan anlayışı değişmekte ve yerini yeşil altyapıya bırakmaktadır. Yeşil altyapı; ekosistem değerlerini ve işlevlerini koruyan, ekosistem hizmetlerini sunmak için tasarlanan yarı doğal ve kültürel alanların oluşturduğu bir yeşil alan ağıdır. Yeşil altyapı, doğa tabanlı çözümlerle birlikte iklim değişikliğiyle mücadelede kentlerin dayanıklılığını artırmada önemli bir araç olarak tanımlanmaktadır (DKM, 2019). Yeşil altyapı parçacıl alanlar planlamaktan çok bir ağ/network planlamasıdır ve bu özelliği nedeniyle insan/canlı hareketlerini temel almıştır (Atmiş, 2016). Erdönmez ve Atmiş (2020)'a göre İstanbul'da doğal ve yarı doğal alanların bütünleşik birlikteliğinden oluşan bir yeşil altyapıdan söz etmek olanaklı olmamakla birlikte, kentin kuzeyinin doğal ormanlarla çevirili olması sayesinde yeşil altyapı açısından son derece önemli olan bazı avantajları bulunmaktadır.

Yeşil altyapıyı oluşturmak için; kent ormanı, yeşil yollar, çok fonksiyonlu tarım, yaban yaşam geçişi, biyolojik çeşitlilik iş parkı, yeşil çatı ve duvarlar, bitkisel çitler, yol kenarı ve refüj bitkilendirmeleri gibi birçok araç kullanılabilmektedir (Atmiş, 2016). Yeşil duvarlar yeşil altyapının önemli bir alt sistemidir. Fakat; otoban çevresinde uygulanmakta olan yeşil duvarların başka hiçbir doğal, yarı doğal ya da kültürel yeşil altyapı unsuru ile ilişkilendirilmesi ve entegre edilmesi söz konusu değildir. Bu çeşit yeşil duvarlar bütünüyle bağımsız, parçacıl düzenlemelerdir ve bu nedenle yeşil altyapı anlayışı açısından hiçbir anlam ifade etmemektedir. Diğer yandan yeşil duvarların istenmesi durumunda çeşitli yapıların duvarlarını kaplayan sarmaşıklı duvarlar şeklinde olması, hem estetik hem ekonomik hem de o bina özelinde sıcaklık dengesini sağlaması açısından kullanılabilir bir tercih olarak değerlendirilebilir. Fakat bu uygulamanın yeşil altyapı sisteminin parçalarından sadece biri olduğunu unutmamak gerekir.

\section{Sonuç ve Öneriler}

Yeşil duvarlar, son yıllarda dünyanın birçok bölgesinde kullanılıyor olmasına karşın tartışmalı bir uygulamadır. Bu konuda çok sayıda çalışma olup hemen hemen tamamına yakını binaların dış duvarlarının yeşil doku ile kaplanması üzerinedir. Bu uygulamanın amacı estetik görüntü sağlama, enerji tasarrufu, karbon salımının azaltılması ve bina için sıcaklık dengesinin sağlanmasıdır. Üstelik bu tür yeşil duvar uygulamaları kamu finansmanıyla değil, şirketlerin veya bina sakinlerinin kendi özel kaynakları ile yapılmaktadır. Bu tür uygulamalarla çevre yolları ya da geniş kent içi yollardaki yeşil duvarların karşılaştırılmaması ve aynı faydaların buradan beklenmemesi gerekir. Bu bağlamda çözüm için aşağıdaki öneriler dikkate alınabilir:

-İstanbul'da ve benzer illerdeki ormanlar bir yandan çeşitli nedenlerle tahrip edilirken diğer yandan yeşil duvarlar ile kişi başına düşen yeşil alan miktarını arttırmayı önermek bilimsel bir yaklaşım olamaz. Mevcut doğal ormanların azalması önlenmeli ve bunun yanında şehirlerdeki yeşil alanlar, daha doğru ifadeyle ağaçlık alanlar arttırılmalıdır; Bunun için de başta Kanal İstanbul olmak üzere İstanbul'un doğasına-yeşil dokusuna zarar verecek tüm mega ve mikro projeler iptal edilmelidir.

-Atatürk Kent Ormanı ve Kemerburgaz Kent Ormanı gibi mevcut yeşil alanlara benzer şekilde orman ekosistemini barındıran büyük alanlara yayılmış yeşil dokunun miktarı artırılmalıdır. Hatta Atatürk Kent Ormanı’ndaki gibi “ekosistem hizmetleri”nin çeşitliliğini arttıracak uygulamalar yapılmalıdır.

-Otoyol kenarlarına aşırı masraflı ve aşırı su, kimyasal gübre ve ilaç tüketimine neden olan yeşil duvarlar ve geometrik şekilli süslemeler yerine, Avrupa ülkelerinde olduğu gibi hem gürültüyü önleyici hem de hava kalitesinin artırılmasına yardımcı ve maliyeti çok düşük olan uygun yerli türlerden seçilen ağaç ve çalılar dikilmelidir. Çünkü ağaç ve çalılar, bir kez dikildiğinde ve ilk yıllarda birkaç kez sulandıktan sonra çok düşük su sarfiyatı ve bakım maliyetiyle çok büyük yararlar sağlamaya başlamaktadır. Böylece, yola yakın kısımlardan yamaçlara doğru boyutları giderek artan ağaçlandırmalar yapılmasıyla;

a) Hava kirliliği ve

b) Gürültü kirliliğinin azaltılması yanında,

c) Sicaklık dengesi/biyoklimatik konfor ile,

d) Doğal görünüm ve görsel kalite çok daha fazla ölçüde sağlanmış olacaktır. Böylece minimum maliyetle maksimum fayda oluşturulmuş olacaktır. Üstelik kamu kaynaklarını gösterişli otoban yeşil duvarlarına 
harcamak yerine, bu kaynaklarla o otobanların çevresindeki düşük gelirlilerin yaşadığ yeşil alanlardan yoksun semtlere yeni park ve bahçeler kazandırılması söz konusu olabilecektir.

-Değişen iklim koşullarına uyum sağlayabilecek yapıda, su tüketimi daha düşük seviyede olan, gübreleme ve kimyasal ilaç kullanım ihtiyacı olmayan ya da çok daha az olan bitkilerin tercih edildiği yeni yeşil alanlar oluşturulmalıdır. Bilindiği gibi iklim değişmekte, sıcaklık ve kuraklık artmaktadır. Ek olarak yağışlar düzensizleşmekte, çok şiddetli sağanak yağışlar betonlaşmanın da etkisiyle kent sellerine neden olmaktadır. Kent iklimini düzenleme ve daha yaşanabilir kentler oluşturmaya en büyük katkı, kentlerde açı yeşil alanların ve elbette orman ekosisteminin arttırılması ile mümkündür. Kent 1sı adalarının küçültülmesi/kırılması, insanların gölgesinde oturabileceği, kaliteli vakit geçirebileceği yeşil alanların arttırılması kent yaşamını kolaylaştıracak, serinlemede kullanılan enerjinin de azaltılmasına yol açacaktır. Ne yeşil duvarların ne de pasif yeşil alanların bu bağlamda faydası yeterlidir.

-Tüm dünyada şehirlerin iklim değişikliğinin etkilerine uyumunu sağlamak amacıyla "Yeşil Altyapı” olarak adlandırılan sistemsel uygulamalar giderek yaygınlaşmaktadır. Yeşil altyapının; kent ormanı, yeşil yollar, çok fonksiyonlu tarım, yaban hayvanı geçişi, biyolojik çeşitlilik, iş parkı, yeşil çatı ve duvarlar, bitkisel çitler, yol kenarı ve refüj bitkilendirmeleri gibi birçok parçası vardır. Bu nedenle şehirlerin yeşillendirilmesinde bu parçalardan sadece birine odaklanmak yerine, yeşil altyapı konusuna daha bütüncül yaklaşılmasına gereksinim vardır.

-İstanbul'da insanların doğrudan erişimine uzak olan yeşil duvarlar konusuna odaklanmak yerine başta İstanbul olmak üzere tüm büyük kentlerde kent içine dağılmış ve mümkün olduğunca ekolojik koridorlarla birbirine bağlanmış, insanların gölgesine sığınabileceği park ve korular oluşturulmalıdır. Bu tür park ve korular yüzeysel akışı azaltıp, yağış sularının toprağa sızmasını sağlayarak kent sellerinin oluşmasını azaltacaktır. Diğer yandan bu doğal ekosistemler kentin serinlemesine katkı sağlayacak, dolayısıyla kentsel 1sı adası oluşumlarını azaltacaktır.

-Kentin yeşil alan miktarını arttırmak için dereler de farklı fırsatlar sunmaktadır. Kent içindeki dereler beton duvarlar içine hapsedilmek yerine kent peyzajının bir bileşeni haline getirilmeli ve gerekli yapısal ve bitkisel düzenlemeler yapılarak kent içi rekreasyon olanakları artırılmalıdır. Böylece yeşil alanlar arasında bağlantılar kurularak yeşil altyapı sistemlerinin oluşmasına hizmet edilebilir.

\section{Kaynaklar}

1. Atmiş, E., 2016. Kentlere Soluk Aldıran Bir Sistem: Yeşil Altyapı. SÜSBİR Haber Dergisi 6: 64-67.

2. Boudjellal, L. and Bourbia, F. 2018. An evaluation of the cooling effect efficiency of the oasis structure in a Saharan town through remotely sensed data. International Journal of Environmental Studies. 75 (2) 309-320.

3. Cengiz, S., Atmiş, E. and Görmüş, S. 2019. The impact of economic growth oriented development policies on landscape changes in Istanbul Province in Turkey. Land Use Policy, 87. 104086.

4. Çabuk, S., 2019. Modern Türk Şehir Planlamasında Aktif Yeşil Alan Standardı: Kayseri Şehir Planlarında Zamansal Bir İnceleme. Bartın Orman Fakultesi Dergisi, 21(2): 280-291

5. DKM, 2019. Yeşil Altyapı-Avrupa'nın Doğal Sermayesini Geliştirmek Avrupa Komisyonu Bildirimi (Türkçesi Senem Tuğ Aksöyek). Ankara. 59s.

6. Doğru, A.Ö., Göksel, C., David, R.M., Tolunay, D., Sözen, S., Orhon, D. 2020. Detrimental environmental impact of large scale land use through deforestation and deterioration of carbon balance in Istanbul Northern Forest Area. Environmental Earth Sciences, 79: 270.

7. Ekşi, M. 2020. Dikey bahçeler üzerine. Arkitera. https://www.arkitera.com/gorus/dikey-bahceleruzerine/

8. Erdönmez, C. ve Atmiş, E. 2020. Yeşil Altyapı ve Kültürel Ekosistem Hizmetleri: İstanbul Yeşil Alan Planlanması Açısından Çıkarımlar. İstanbul Yeşil Alanlar Çalıştayı. İstanbul Büyükşehir Belediyesi yayını. 5-6 Şubat 2020. S: 320-334. İstanbul.

9. Gül, A., Dinç, G., Akın, T. ve Koçak, A.í. 2020. Kentsel Açık ve Yeşil Alanların Mevcut Yasal Durumu ve Uygulamadaki Sorunlar. İdealkent Kent Araştırmaları Dergisi, 11: 1281-1312.

10. Hızal, A., Serengil, Y. 2008. Havzalarda temiz tatlı su üretimi. Küresel İklim Değişikliği ve Su Sorunlarının Çözümünde Ormanlar. Bildiriler Kitabı: 131-134.

11. İBB, 2020. İstanbul Büyükşehir Belediyesi Açık Veri Portalı. https://data.ibb.gov.tr/dataset/2019-yilipark-bahce-ve-yesil-alan-verileri/resource/1d9762dc-b3ea-43f1-a46b-2eb0884d26e1 (Erişim Tarihi: 03 Ocak 2021). 
12. Jauregui, E. 1990. Influence of a large urban park on temperature and convective precipitation in a tropical city. Energy and Buildings 15 (3-4): 457-463.

13. Koca, H., Yaman, B., Aydın, Y.M., Altık, H., Kara, M., Dumanoğlu, Y., Bayram, A., Odabaşı, M., Elbir, T., Tolunay, D. 2013. Türkiye'deki ormanlık alanlardan kaynaklanan biyojenik uçucu organk bileşiklerin (BVOC) emisyon envanterinin hazırlanması. V. Hava Kirliliği ve Kontrolü Sempozyumu (HKK2013). S.331-342.

14. Manso, M., Castro-Gomes, J. 2015. Green wall systems: A review of their characteristics. Renewable and Sustainable Energy Reviews. 41 (863-871).

15. Nichol Janet E. 1996. High-resolution surface temperature related to urban morphology in a tropical city: a satellite-based study. Journal of Applied Meteorology, 35: 135-146.

16. Nowak, D.J., 2000. Tree species selection, design, and management to improve air quality. 2000 ASLA Annu. Meet. proceedings.

17. Nowak, D.J., Greenfield, E.J., Hoehn, R.E., Lapoint, E., 2013. Carbon storage and sequestration by trees in urban and community areas of the United States. Environ. Pollut. 178, 229-236.

18. Oliveira, S., Andrade, H., Vaz, T. 2011. The cooling effect of green spaces as a contribution to the mitigation of urban heat: a case study in Lisbon. Build. Environ., 46: 2186-2194.

19. Öztürk, M., 2020. Dikey bahçeler, yaşayan duvarlar, yeşil duvarlar. Independent Türkçe (17 Ekim 2020 tarihli yazı). https://www.indyturk.com/node/258581/t\%C3\%BCrki\%CC\%87yeden-sesler/dikeybah\%C3\%A7eler-ya\%C5\%9Fayan-duvarlar-ye\%C5\%9Fil-duvarlar (Erişim Tarihi: 03 Ocak 2020).

20. Perez, G., Rincon, L., Vila, A:, Gonzales, JM., Cabeza, L.F. 2011. Behaviour of green facades in Mediterranean Continental climate. Energy Conversion and Management. 52: 1861-1867.

21. Renterghem, T. von, Forssen, J., Attenborough, K., Jean, P., Defrance, J., Horniks, M., Kang, J. 2015. Using natural means to reduce surface transport noise during propagation outdoors. Applied Acoustics, 92: 86-101.

22. Şahin, A. 2020. İstanbul ve Çevresinin Orman Varlığı. Şu eserde: Akkemik, Ü. (Ed.). Ekosistem, İklim ve Kentsel Büyüme Perspektifinden İstanbul ve Kuzey Ormanları. Türkiye Ormancılar Derneği Yayın No:50, Marmara Şubesi Yayın No: 4, İstanbul. ISBN: 978-975-93478-7-1. s: 24-55.

23. World Cities Culture Forum, 2021. Percentage of public green space (parks and gardens). http://www.worldcitiescultureforum.com/data/of-public-green-space-parks-and-gardens. (Erişim Tarihi: 03 Ocak 2021).

24. Yu, C., Hien, W.N. 2006. Thermal benifits of city parks. Energy and Buildings, 38 (2): 105-120.

25. Zaid, S.M., Perisamy, E., Hussein, H., Myeda, N.E., Zainn, N. 2018. Vertical Greenery System in urban tropical climate and its carbon sequestration potential: A review. Ecological Indicators. 91: 5770. 